\title{
Staff Development as an Imperative Avenue in Ensuring Quality: The Experience of Adama University
}

\author{
Yilfashewa Seyoum \\ Faculty of Education and Behavioral Sciences, Haramaya University, C/O Fekadu Chernet, P.O. Box 5012, Adama University, Ethiopia \\ Correspondence should be addressed to Yilfashewa Seyoum, yilfa_sey@yahoo.co.in \\ Received 25 March 2012; Revised 31 July 2012; Accepted 31 July 2012 \\ Academic Editor: Eric Z. F. Liu \\ Copyright () 2012 Yilfashewa Seyoum. This is an open access article distributed under the Creative Commons Attribution License, \\ which permits unrestricted use, distribution, and reproduction in any medium, provided the original work is properly cited.
}

All endeavors were devoted to investigate the views and feelings of stakeholders on the implementation of teachers' professional development and its contribution to sustain academic programs quality at Adama University. A case study that constitutes qualitative and quantitative method was employed. In an attempt to achieve the objectives of the study, evidences were collected from students, staff members, professional development program coordinators, and management bodies. The data-collecting instruments for obtaining relevant information were questionnaires, interview, observation, and document analysis. The finding in relation to this study uncovers the fact that though continuous professional development has been perceived as the most useful avenue of teachers continuous and lifelong learning, for the most part, it is relegated to adhoc committees or interested group or institutional units in the system of university education/training. Moreover, the absence of PDP in the university organizational structure, clear mission and vision, defined and well-articulated policy, strategic plan, representatives in university senate meetings, adequate resources, well-identified and -preserved training facilities, and unit library were circumstances that in one way or another negatively affected the provision of effective professional development programs/trainings that may have adverse effect in the deliberation of quality education/training in Adama University.

\section{Introduction}

The continuous revision of curricula and development of new and unusual academic programs demands a system to train and retrain instructors and academic leaders on continuous bases. To this end, staff and professional development programs become a foreseeable strategy that higher education institutions should build in their system in order to survive in the current changing demands and accountability. Thus, since professional development is a vital element to the survival and growth of higher education systems, institutions must carefully plan and implement professional development programs to muddle through these different pressures. And, in order to be successful, the professional development programs need to be taken into account both for the benefits of the staff and the institution $[1,2]$.
In order to resolve many of the academic pressures and make timely response for those policy matters, the Ministry of Education has integrated academic and professional development programs in Ethiopian higher education reform. To this end, in relation to the improvement of institutions and teachers' professional competencies, the Ministry of Education in collaboration with donors has been conducting the following programs:

(i) The Higher Diploma Program (HDP),

(ii) The English Language Improvement Program (ELIP), and

(iii) Academic Development and Resource Center (ADRC).

Although it seems that there is variation in their designations, these programs have comparable purpose. They are 
geared towards augmentation of the professional competencies of university teachers with the aim of enhancing students learning.

Presently, huge projected like General Education Quality Improvement Program (GEQUIP) has been striving to reform and strengthen PDP both at the ministry and institutional levels [3]. The GEQIP has been under implementation at three levels of government; Federal, Regional, and Woreda levels-Universities at the Federal level and Colleges of Teacher Education (CTE) at the regional level have been responsible for teacher development activities in close coordination with the MOE and REBs, respectively. It is seriously examined that, under the first round of TDP, the Continuous Professional Development (CPD) program was provided ongoing training for those teachers. However, a scholarly monitoring of the CPD program showed that it was haphazardly implemented, seldom translated into the languages of teachers best understood, and delivered in a lecture format inappropriate for the adult learning that CPD should foster [3]. Therefore, the new involvement of GEQIP is to be able to avoid these consistencies and fill the gap between plan and practices of the current teachers professional development programs [4].

It is strongly underpinned that professional development activities through professional training and interaction improve university instructors' professional proficiencies and the quality of student learning. Indeed, it is based on the empowerment and dedication of teachers to take ownership of improving their continuous practices, seeking for innovation, which according to Fitz-Gibbon in Visscher and Coe [5] means more endeavors and something unique for the instructors. Improving the work of staff members would mean enabling them to acquire new experiences in something different manner. Taking appropriate measures such as humanizing teaching, team spirit, collegiality, and research excellence through continuous training in methods of teaching, curriculum development, assessment of the outcome of teaching, and learning a few of the many important dealings is to consider [6].

Nevertheless, studies in relation to quality education signify that among the factors affecting quality of teaching in Ethiopian higher education institutions is the fact that pedagogical training has not been a prerequisite for teaching. Abyot [7] in his study found that professors in higher education institutions in the country did not have instructional skills training. According to this study, university instructors are said to be

\section{Male dominant (97\%), had little or no staff development either before or after assignment as an instructor. They were assigned rather than being selected following competition to enter into the profession. Hence, enriching professionalism has never had a significant place through out the life span of modern education in Ethiopia [7].}

Meanwhile, in a recent attempt for improving instructors professional competencies, teacher's reaction to the various initiatives was not encouraging. For example, Minale [8] after studying the condition of Addis Ababa University further clarified that the level of organizational support to the professional training and mainly the implementation appears to be not so much valued by participants (the higher diploma program candidates). Specifically, they are not happy with the absence of followup of implementation, lack of reward for the training; scarcity of resources as well as problem of classroom layout.

Review of related literature in the field of professional development disclosed the fact that there is remarkably little empirical research that informs our understanding of the relationship between professional development policies and practices to secure improvements on professional competencies of instructors and ensure quality learning. In the meantime, few efforts have been made to assess the policy and the outcome of professional development beyond the brief responses requested at the conclusion of workshops that solely depend on participant reaction [9]. To this end, this teacher's professional development investigation is aspired to begin to fill this gap. The study is directed to describe and analyze the problem under the title "Staff Development as an Imperative Avenue in Ensuring Quality: The Experience of Adama University." And, in order to carry this out, the following leading questions were formulated.

(i) What types of professional development (PD) frameworks were being provided?

(ii) How much support has been exerted to facilitate the implementation of $(\mathrm{PD})$ ?

(iii) To what extent instructors were satisfied with the (PD) opportunities?

(iv) How can quantitative and qualitative difference be secured on teachers' behavior and the existing institutional culture through (PD) programs?

It was expected that endeavors to resolve the above queries would lead to an exploration, description, and explanation of the present direction of staff development programs in Ethiopian Higher Education Institutions in general and the university under study in particular. Above all, it would have magnificent role to design relevant and apposite staff development programs in the future.

1.1. Objectives of the Study. The overall aim and objective of this study was to analyze the implementation practices of Professional Development Programs in Adama University. In more explicit manner, the study has the following objectives:

(i) explore the most frequently employed frameworks of (PD) practices,

(ii) investigate the extent to which (PD) programs were well implemented,

(iii) determine the appropriateness of existing (PD) initiatives,

(iv) analyze how much improvement have been brought on practices and the instructors skills, knowledge, and attitudes as a result of teachers (PD) activities, and 
(v) Suggest new and alternative model of professional development.

1.2. Significance of the Study. The overall intention of this study was to investigate the activities of policy formulation, implementation as well as the impact of various professional development programs on instructors' professional competencies in Ethiopian Higher Education Institutions. It is anticipated that instructors need to up-to-date themselves through professional development that fits to the changing situations and realities [10]. To this effect, this study has the following key educational contributions.

(i) It will open room to understand more on the nature and mode of processional development program in the context of university academic program milieu.

(ii) It will possibly clarify the challenges and opportunities of the existing professional development program implementation.

(iii) It will give direction for curriculum planner and developer to endorse and integrate the preeminent professional development frameworks in the process of curriculum implementation.

In general, the study could serve as a stepping stone for initiating other researchers in a wider scale on the same issue or related as a means to improve the quality of education in Ethiopian Higher Education Institutions.

1.3. Context of Adama University. Adama University was recognized in 1993 as Nazareth Technical College and later Adama Technical Teachers College up to its inauguration as a university in 2005. Currently, this university has several schools and departments. The University has been organized under six major schools, namely, School of Engineering, School of Business and Economics, School of Humanities and Natural Sciences, School of Pedagogy, School of Health Sciences, and School of Agriculture. The former four schools were established at Adama campus, and the later two are instituted at Assela campuses. Currently, Adama University runs both undergraduate and postgraduate programs including teachers' professional development programs, Pedagogical Skills Improvement and Support Center (PSISCS).

The researcher selected this university, considering that this has been among the relatively experienced university in planning and executing various teachers' professional development programs. The other reason why this study site was taken into account could be linked with the special proximity that the inquirer has to this institution. The research initiator had worked in Adama University for brief period of time. Moreover, he has also conducted many tutorial sessions for distance learners. Meanwhile, while he was pursing the Ph.D. program, the Adama city was the preferred strategic permanent residence of him. Hence, Adama University was found as the best place for visiting libraries and the actual professional development practices in the researcher spare time. Consequently, these opportunities created make him rely on this study site as the most important spotlight of the investigation under consideration.

\section{Review of Related Studies}

2.1. The Nature of Professional Development in HEIs. The Policy Statement of The Queens University of Belfast describes professional development as institution policies, procedures, and practices designed to develop the knowledge, skills, and attitudes of staff and, by so doing, improve the effectiveness and efficiency of both of the individual and the institution [11]. Similarly, according to Human Resource Policy (HRP) of the University of Western Australia, professional development is also a commitment to optimize opportunities for all staff to improve their levels of skills and knowledge to improve the quality of workforce productivity and staff satisfaction [12]. Furthermore, a definition given by the University of Sussex in its Policy statement on staff development was demonstrated as a commitment to the development of its staff through encouraging an environment conducive to learning, and providing resources for learning in a variety of ways [13]. For Piper and Glatter [14], staff development is a systematic attempt to harmonize individuals' interests and wishes, and their carefully assessed requirements for furthering their careers with the forthcoming requirements of the organization within which they are expected to work.

Emphasizing the importance of staff development in increasing effectiveness in the university, it is claimed that staff development facilitates personnel and professional development for individuals and groups, enabling them to achieve their potential and contribute to the provision of excellence in teaching and research in the university [15]. In another contribution, Anyamele [16] emphasizes the importance of staff development in the current changing higher education landscape. According to the report, higher education institutions are highly recommended to put in place appropriate staff development strategies to support all staff and promote involvement in the development and implementation of university-wide policies and strategies. This is because effective staff development is essential to support new approaches to learning and teaching, and meeting the changing needs of institutions.

Scholars like Duke argue that higher education institutions should recognize that their staff members are their vital and valued asset. As a result, Universities should commit themselves to encouraging and enabling staff to realize their potential by providing opportunities for all colleagues to gain the knowledge, skills, and experience necessary for them to enhance their contribution to meeting individual, area, and organizational objectives. Not only that staff development should be among a clutch of institutional innovations thrust upon universities, it is a technique or tool to increase quality, efficiency, and output; it can be associated with high-quality professional performance resulting in career advancement, strategic development, and initiative to sustain change [17]. Thus, the consideration of professional development program in today's university conditions needs to be regarded seriously [18]. In an attempt to explain the relevance of professional development in the university context, scholars refer to as opportunities provided to instructors to develop knowledge, skills, methods, disposition, and so forth that 
help them to effectively deliver classroom instruction, and to improve the students learning [19-21].

In general, professional development is accepted as an inevitable mechanism in implementing the recent higher educational reforms that consider interactive studentcentered teaching and learning approaches as an integral element. It enables teachers to keep them up-to-date to the current educational trends and new theories. It refurbishes teachers' repertoires of knowledge, skills, and attitudes. It also upgrades the problem solving skills of the teachers. Moreover, it has potentials of strengthening friendship and collaborative works and develops the sprit of team work among the staff members to improve the quality of teaching learning. It is also one of the significant means to bring improvement on institutional organizational culture $[6,8$, 22].

\subsection{Professional Development as a Means for Achieving} Quality in HE. Using the quality descriptors, the following characteristics are used to judge the quality of the staffing in the university [23]: sufficient number of specialist staff, good balance of different specialist disciplines, use of external specialists, and well qualified academically. Education policy and various education sector development plan, emphases on the development of teaching skills, good and up-todate industrial or commercial experience, variety of teaching experience, having appropriate specialist expertise, wellgraded age profiles, appropriate ratio of males and females across most grades, appropriate numbers of support staff, well-qualified and -experienced technician staff, good use of administrators, and sufficient amount of secretarial support $[24,25]$.

Brennen [26] argues that higher education staff development is important for two explicit purposes: First, assistance to novice teachers, which will support them to adjust to their new role as they begin their teaching profession, and the second main purpose of staff development is assistance provided to experienced teachers. Although experienced teachers would have overcome these challenges, they too need to improve their existing professional skills. In general, staff development is aimed at the improvement of instruction and learning and thereby a mechanism to secure quality education.

Sustaining quality depends very much on the extent to which the teaching staff members are provided with an opportunity to claim "ownership" and "control" over their own professional practices as a result of which they "experience a deficiency" so as to bring change which turns into improvement $[5,27]$.

\subsubsection{How Does Professional Development Impact Program} Quality? Professional development activities can impact program quality on at least two levels. First, staff development can affect learning outcomes. Evidence of this process comes from other fields. Early childhood education studies have found that the quality of daycare children receive is associated with providers' educational attainment and participation in training workshops and that quality of care is in turn linked with children's more positive social and cognitive outcomes [28]. Similarly, an education reform study showed that elementary school students performed higher in reading and math when their teachers had participated in and given high ratings to a professional development program that provided content knowledge and instructional strategies aligned with state education standards [29].

The positive impact of staff development most likely operates through a chain of events. Professional development activities affect the practices teachers have in their programs, and these practices in turn affect students' continuous performance. For example, well-trained providers use their knowledge of child and adolescent development to interact positively and effectively with students. Research from developmental psychology has shown that having at least one positive and caring relationship with an adult can buffer children against risk factors in their lives and, in fact, can predict positive outcomes in later life [30]. Professional development programs provide a vital opportunity for such connections, whether the program's focus is on academics, leadership skills, or other outcomes [31]. Staff training can also help providers plan enriching activities, connect with participants' families, and communicate with community stakeholders-all of which are elements of high quality programs $[32,33]$.

Secondly, professional development is important because of its potential impact on the sustainability of the youth development workforce. Training providers who have professional development opportunities have reported feeling more confident and more satisfied with their jobs [31]. These outcomes could lead to better staff retention and lower turnover rates. It is important to emphasize the possibility; however, that staff retention may improve only if staff that have training opportunities also have opportunities for increased responsibility and higher compensation. One method for addressing this need is the career development ladder; a system that would tie increases in information in these evaluations, usually limited to hiring qualification and staff/child ratios. This could be due to a number of barriers, including limited time and resources for evaluation and limited evaluation skills $[32,33]$.

It is therefore quite straightforward to regard teachers' professional development for its immense contribution to quality of teaching staff, quality of students learning, and overall quality of institutional achievement in the circumstance of higher education.

\subsection{Professional Development Practices in Ethiopian Uni-} versities: A Situational Analysis Drawn from Institutional Audit Report of Seven Universities. In an effort to critically examine the existing professional development programs and the major achievement of Ethiopian higher education, the researcher was highly involved in studying relevant documents. One way of doing this was scrutinizing the tracer studies conducted during an institutional audit through HERQA in some of the Ethiopian universities. To this end, the reports of seven relatively old universities (as their 
documents were accessible) were reviewed and discussed as shown below.

2.3.1. Adama University. Keeping in mind the staffing profile of the university, it was assumed that staff development has been an essential component to the creation of an academic workforce capable of meeting the demands of the vision and mission of the university. It is suggested that the university should pursue a variety of means to meet staff development needs and not place reliance on the gaining of scholarships for further study. Above all, the university needs to have a budget for staff development and a comprehensive staff development plan that seeks to fill staffing needs and not just rewards achievement.

The HERQA/audit team concluded that Adama University did not appear to have a comprehensive target approach to staff development. No documentation was available to the audit team as evidence of previous staff development activities or, with the exception of an action plan from ADRC, concrete plans to provide staff development in the months ahead. The Adama University Five Year Strategic Plan of 2007 recognizes the center as important, but it deals only in area of staff training. Meanwhile, the ADRC staff as reported to the HERQA team pointed out that while they were seeking to fulfill their responsibilities, they lack the support from the university management who has not responded to their action plans nor supplied resources to properly establish the center. They also voiced the view that as they do not have seat at senate, they lack visibility and power. The HERQA team suggested that the role of the ADRC needs clarification, that it needs greater recognition as allocation of budget for its proper establishment and activities of the professional development initiatives [34].

2.3.2. Hawassa University. The HERQA team was of the view that the university has made a strong commitment to training and will need to continue to do so. It will have to look for training opportunities via each of the routes (shortterm versus long-term training) as it has recognized both in Ethiopia and overseas. The audit team acknowledges the initiative of the university in developing its own training capacity which was seen as an area for growth.

The Academic Development and Resource Center (ADRC) was established in the university under the EQUIP project. The Center has established a sound base for its work which falls into three areas: staff development, quality care, and provision of resources where a number of books related to teaching and assessment for staff are available to borrow but also have items of equipment to aid the teaching staff. It was realized that its main activity was staff development. As reported above, the ADRC had provided pedagogical training. Since it is founding, it has been in an establishment and development phase and now is moving into a delivery phase. The ADRC was found to be an important unit for staff development, arising from quality enhancement initiative [35].

2.3.3. Haramaya University. The university has a good record of sending BA/BSC-holding graduate assistants to MA/MSc studies in no later than two years from appointment. However, such further training tends to focus on knowledge extension and research skills development and not on pedagogy and thus; when the staffs return, they have been in no longer a position as far as teaching proficiencies is concerned.

At the time of the audit, the ADRC had no recognized status in the organizational structure of the university and did not appear on the organogram. It was the view of the HERQA team that the relationship of the ADRC with the departments and colleges needs to be well established so that there would be good awareness of its functions and enabling faculties, departments, and individual instructors to take advantage of its services.

The HERQA team learned that the Haramaya University ADRC has provided staff development courses on instructional skills and assessment. They also learned that members of staff were initially reluctant to attend training sessions but were required to do so by the university. However, once they were participating, they found it interesting and satisfying as it equipped them with important knowledge, skills, and predispositions [36].

2.3.4. Gondar University. During the time of audit assessment, it was realized that the ADRC was supposed to play a key role in staff development. However, how this center was organized and integrated into the Gondar University structure was somewhat ambiguous. From discussion with that the University Quality Assurance Team, the HERQA team learned the ADRC was the only operating unit under the Quality Assurance and Enhancement Office but without any clear terms of references.

The team had reviewed the 2000 E.C Annual Plan document particularly the annual plan of the quality assurance and enhancement office. It was suggested that even if this office had a comprehensive plan for the year, greater emphasis should be placed on issues related to academic staff development, extending beyond a strategy of shortterm training in pedagogical skill development. The office should also seek means of linking staff appraisal to its staff development activity [37].

2.3.5. Mekelle University. The university has been aware of the need for staff development and has provided several opportunities. The Higher Diploma Program (HDP) for staff in the Faculty of Education has been well established. Notably, the ADRC has organized training on instructional skills and in other areas. These courses have been aimed at new staff, but it was learned that the numbers of new staff requiring training had not been able to be accommodated on courses.

The ADRC was principally a staff support and development unit and, as such, has a major role in providing advice on matter of teaching, learning, and assessment and in helping staff with the production of teaching and learning materials and in designing tools to help enhance quality. The $\mathrm{ADRC}$ in the university was established and has been running staff development courses. The center has a master plan to 
guide its future development. The HERQA team realized that while it was learned that the ADRC was planning to provide courses, it has yet secured a budget from the university. The HERQA team had seen the ADRC as an important agent of change and development in the university and a key for improving the quality of teaching learning and assessment [38].

2.3.6. Bahir Dar University. Having recognized the importance of upgrading the staff, the university had produced a staff development policy. The main objective of the policy, as stated in the document, includes enhancing excellence in teaching and research activities. The HERQA team confirmed that, with the overall intention of improving the quality of instruction and assessment, the university has established a professional development center, ADRC and initiated the Higher Diploma Program (HDP) and the English Language Improvement Program (ELIP). The HERQA team learned from the meetings with Heads of Faculty and Heads of Department that all the new members of the academic staff are invited to attend an induction program organized by ADRC.

The HERQA team was informed that the HDP provides a well-organized 10-month training program to all members of the academic staff of the Faculty of Education. Every member of the academic staff in the faculty is required to take the HDP. Success was rewarded by certificate recognizing the holder as a professional teacher educator. The HERQA team learned that members of staff of the faculty were very satisfied with effectiveness and efficiency of the training provided by HDP. Meetings with representatives of staff from other faculties indicated that they too needed HDP-type training but could not get it [39].

2.3.7. Arba Minch University. This HDP training was limited to the teachers' educators, that is, instructors at the Faculty of Education has recently commenced to practice active learning methodologies. It would be useful to extend this training to other faculties as it would provide the academic staff, the majority of whom were juniors with no pedagogical backgrounds, with practical skills to support their development as effective teachers and reflective practitioners with enhanced professional status.

The ADRC was developing and offering courses, which was believed as an important vehicle for staff development. It needs the support of the university in terms of providing the resources (training facilities, staffing, and budget) to be able to strengthen it and to contribute to quality enhancement initiatives [40].

To conclude, from the above quality audit reports, it is quite possible to have common indulgent of the present professional development programs established in higher education institutions on two major targets: securing staff professional competencies and supporting the academic programs for keeping quality education through the enhancement of student learning. From the critical review of the above audit report, it is clear that higher education teachers' professional development program has been institutionalized. However, due to lack of clearly defined policies and lack of resources, the outcome of professional development practices was not up to the expected level. Consequently, the lack of services or in appropriate functioning might cause the downgrading of teachers' professional competencies and impede the innovation that might result in low achievement and dissatisfaction on the part of students that in turn may ultimately lead to educational crisis-inappropriate and low quality education. More importantly, from the observations conducted by HERQA, it can be inferred that the contribution of teacher professional development practices (for assisting and improving the delivery of academic programs in order to attain quality education at different ladder of the academic programs) is paramount. It can also be inferred that the various professional development programs in Ethiopian universities anticipated to serve as a means to achieve individual and institutional improvement, keeping in mind that there are appropriate support and followup system in place through coordinating and management bodies. Nevertheless, the present system of professional development seems suffer with lack of well-defined policies, resources, recognition, and attention on the part of the management bodies.

\section{Method}

3.1. Research Design. Since the study was planned to make an in-depth analysis of mode of PDP, implementation, and the status of the professional development at Adama University, it can be taken as a case study. Case studies emphasize detailed contextual examination of a limited number of events or conditions and their relationships explored through the use of one or more cases within a setting or context [41]. In an attempt to provide in-depth understanding and allow for use of multiple data sources, both quantitative and qualitative data, mixed methods, were used. A mixed methods research "combines or associates both qualitative and quantitative forms" [42] and is useful when "the strengths of both quantitative and qualitative research can provide the best understanding." It is the belief of the researcher that when both approaches are combined in a single study, the outcome has greater breadth and depth [43].

3.2. Population and Sample. In this study, the issue to be investigated was professional development, and the education structure was higher education specifically universities in Ethiopian condition. As the result, the respondents for the given study were the group containing all university instructors, HoDs, faculty deans, and management bodies who have been involved in developing, receiving, and/or organizing the professional development programs in the study sites under consideration. Moreover, individuals who were directly or indirectly involved in policy formulation (people who were involved in preparation of policies, guidelines, blue prints, etc.) and decision making at Ministry and institution levels were also part and parcel of the study. 
3.3. Data Collecting Instruments. The tools designed to collect data were interviews, questionnaires, document analysis, and observation. In this study, the data required were teachers, program leaders, and top managers' views who in one way or another involved in planning and executing teachers' professional development programs. Moreover, written documents related to teachers professional development practices were also important sources of information.

3.4. Data Collecting Procedures. The necessary information was collected from the respondents directly by making a face-to-face interview, distributing questionnaires in their own place and at their own conveniences. In this way, the researcher had got good opportunity to meet and talk with respondents to be able to avoid unnecessary skepticisms and haziness. For example, the researcher by availing himself in the study site delivered oral instructions in addition to the written directions given on those data collecting tools. Moreover, the investigators had got first-hand information about the activities of professional development efforts through observation by directly availing himself at the study site. It was the belief of the inquirer that such procedures for collecting information increased the credibility and validity of the data procured.

3.5. Method of Data Analysis. Two major techniques of data analysis were employed: qualitative and quantitative data analysis. In general, specific techniques include placing information into arrays, creating matrices of categories, creating flow charts or other displays, and identification of thematic areas were some of the methods considered in qualitative analysis [44]. The quantitative data (information procured through questionnaires) were analyzed with rules following parametric statistical tests as $Z$-test, Analysis of Variance and Product Moment Correlation techniques. Meanwhile, considering its appropriateness, the Chi-square statistical analysis for testing the significance difference between observed and expected frequencies was also incorporated.

\section{Results and Discussion}

In an attempt to organize four thematic areas that were emerged from the findings of this study were considered. These core points were

(i) mode of the professional development programs,

(ii) implementation of the professional development programs,

(iii) appropriateness of the professional development programs, and

(iv) improved practices as the consequence of professional development programs.

\subsection{Typology of the Professional Development (PDP) at Adama University}

4.1.1. Teachers Conception of Professional Development. When one tries to examine studies in the field of professional development, he/she could view as the body of systematic activities to prepare teachers for their job, including initial training, induction courses, in-service training, and continuous professional development within institutional settings. When this definition of professional development is compared to the definition used in Guskey [10], the perspectives seem similarly broad "Professional development is defined as activities that develop an individual's skills, knowledge, expertise and other characteristics as a teacher." The purpose of professional development in essence is to enhance students learning.

However, in an interview conducted with the different audience of the present study, the meaning of professional development varies from individual to individual, from institution to institutions, and for purpose it stands for. The following were some of the understanding of respondents on the conception of professional development.

(i) It is a kind of continuous training to improve ones skills and knowledge in teaching, and the intention is to support curriculum implementation.

(ii) It is a process or a program designed to improve the proficiencies of practitioners. In this case, teachers and educational management personnel can be considered as practitioners. The activities that can be described under professional development are training, discussion, seminar, and experience sharing of best practice.

(iii) It is a program to enable instructors more up-to-date and self-directive. The intention is to make academic staff effective in teaching. Mainly the activities are embedded in training. This enables us to keep and foster quality in education/training.

The respondents who took part in this study were asked to enunciate the meaning of professional development in the context of their practice. The responses provide evidence of the complex nature of the concept as argued in the literature. From the explanation given, it was not difficult to conclude that many of the instructors and academic leaders had not been previously given any thought to professional development, and therefore the notion was essentially unfamiliar to them.

Interestingly, the embedded and potentially hidden nature of professional development appears to result in some academics perceiving professional development as being those areas of learning that lie outside their daily working practices. Thus as one participant describes professional development as being "... developing skills that you do not develop through teaching or that are outside of your own subject area but they are things that you need to do, so like computing training for when you have to do administrative tasks." Conversely, some of those interviewed described professional development as being that "which enables practitioners or academics or teachers to fulfill their day job and to keep themselves up to date."

4.1.2. The Type of Training Modules Included in the Professional Development Program. In Adama University, the 
TABle 1: Professional development training modules at Adama University.

\begin{tabular}{lcc}
\hline Module & Title & Hour \\
\hline Module 1 & Reflective teacher & $8 \mathrm{hrs}$ \\
Module 2 & English for communicative skills & $18 \mathrm{hrs}$ \\
Module 3 & Information technology & $24 \mathrm{hrs}$ \\
Module 4 & Developing active learning & $16 \mathrm{hrs}$ \\
Module 5 & Improving assessment & $14 \mathrm{hrs}$ \\
Module 6 & Action/applied research & $10 \mathrm{hrs}$ \\
Module 7 & Industry and TVET school placement & $16 \mathrm{hrs}$ \\
\hline Total & & $106 \mathrm{hrs}$ \\
\hline
\end{tabular}

existing type of professional development coordinating center has been referred as Pedagogical Skills Improvement and Support Center (PSISC). The center is responsible for organizing and/or give support in various training. In the training given by PSISC, the following training modules have been included (see Table 1).

As a whole, in the university teaching milieu, professional development means training and seven modules with 106 hours have been designed and enacted for at least a period one semester. It means dominantly, the provision of different modules like the above was considered as the sole means of professional development initiatives.

In the documents study, the history of higher education teachers' professional development practice in Ethiopia started with the initiatives of UNESCO with the creation of a National Pedagogical Resource Center [45]. This was followed by the Higher Diploma Program (HDP). HDP is a one year on-the-job training of teacher educators, mainly on such themes like active learning, reflective practice, continuous assessment, and action research [8, 22, 46]. Furthermore, starting from the academic year 2005/06 an attempt had been made to institute the Academic Development and Resource Center (ADRC), and one of the main roles of this center was continuous professional training. Hence, from the above explanation, it can safely be said that the history of teachers' PD was dominated by INSET through centers like HDP, ADRC, and the like. As one respondent interviewed and reflect it:

\section{Before, we had ADRC, HDP, ELIP and other short training as major means of teachers' professional development deliberations. Now it is changed. The present professional development coordinat- ing centre named as PSISC. It is a recognized professional development centres and has its own module, assigned human power.}

Overall, it can be inferred that he present system of PD training cannot be fully concluded as a kind of training that is given continually and comprehensively. The PD training is seasonal rather than continuous. However, the literature on professional development in higher education emphasises continuity, variety and collaboration as a key component [47, 48].
4.2. Implementation of the PDP at Adama University. The data secured through interview displayed the importance of psych-social and resource factors inhibiting the professional development opportunities. In the case study interviews, there were feelings of having to comply with external agendas rather than self regulate with regards to professional development needs and provision. In most cases, teachers experienced the tension between personal, individual interests and needs and the demands of national and local initiatives for the time spent in professional development.

4.2.1. Facts about the Implementation of the Programs. In order to examine the current situation in the implementation of professional development programs, teachers' questionnaire was prepared and applied as a tool. In general, the questionnaire consists of four dimensions. These were transferability of professional development experiences, accessibility of the necessary resources, support from colleagues and program leaders, and consideration of time for professional development practices. Availability of the professional development event was established by the respondents "yes" response. Thus, the observed figures show the number of yes corresponding to each statement in the questionnaire (see Table 2).

In order to examine the gap between observed and expected events in the professional development practices, the Chi-square test of equal probability was adapted. Consequently, the calculated value of chi-square notified as there was a significant difference between dream and realities at 0.01 level of significance with degree of freedom equal to 3. This refers to there was consistent difference between observed and anticipated events in the implementation of professional development programs. From this, it can be suggested that the need to device appropriate strategies to enhance the feasibility of professional development program with the allocation of necessary resources, provision of enough time and arrangement of necessary support to the implementation of professional development scheme need urgent prioritization and attention. Bahr et al. [49] noted that successful professional development is "a process, not an event" and reported considerable evidence that one-off professional development events seldom have any impact on teachers or their practice. This is because of the considerable time required to understand an innovation and to then reflect on and change teaching practice [50]. Fullan, [51] lays important groundwork before and during the production phase of a professional development program, and that frequent communication and open discussion of the program's merit for coping with felt need must maintain and develop an awareness of this topic during the implementation process (see Table 3).

To analyze whether factor such as sex brought variation in perceptions of instructor about the implementation of professional development program, Chi-square for testing hypotheses of independence was employed. In this way, the calculated value of Chi-square equal to 2.66 assured that it was not significant even at $\alpha=0.05$. Consequently, hypothesis of independence was accepted. It can therefore be concluded 
TABLE 2: The significance difference between observed and expected frequencies in the implementation of PD programs.

\begin{tabular}{lccl}
\hline Dimensions & Observed & Expected & \\
\hline Experience & 3 & 5 & \\
Resources & 4 & 11 & Chi-square $=22.7$ \\
Support & 8 & 29 & \\
Time & 1 & 4 & \\
\hline Total & 16 & 49 & \\
\hline
\end{tabular}

TABle 3: The implementation of PD in Adama University when sex is considered.

\begin{tabular}{lcccl}
\hline Frequencies & Male & Female & Total & \\
\hline Observed & 20 & 9 & 29 & Chi-square $=2.66$ \\
Expected & 99 & 21 & 120 & \\
\hline Total & 119 & 30 & 149 & \\
\hline
\end{tabular}

that sex has no relationship or has no influence on the responses of audience on the implementation practices of the professional development programs. Meaning, sex was not an important factor to bring differences between perceptions of male and female respondents.

4.2.2. Teachers Perceptions of Professional Development Events. From the Table 4, it can easily be inferred that professional development initiatives were given great opportunity for teachers to improve their teaching awareness and skills. In their perceptions among the events of professional development activity, teachers have given top priority for this one. The event was followed by instructors perceptions that claimed professional development for attainment of institutional than individual need. On the other hand, the existence of too many trainings and the taking of part in setting agenda for the current professional development practices were given least priorities as perceived by the majority of respondents.

Eminent authors asserted that effective professional development should firstly be aware of and address the specific needs of teachers [52]. Once these needs have been identified, activities need to be properly planned to support teachers in applying the knowledge and teaching methodology creatively and confidently [53]. Collinson [54] states that the best results likely to be obtained if the program is formally and systematically planned and presented with the focus on enhancement of personal and professional growth by broadening knowledge, skills, and positive attitudes [5557].

4.3. Appropriateness of the PDP at Adama University. When interview sessions were conducted with various teachers and program leaders, they expressed their feeling on how much the current professional development initiatives were appropriate to their life and towards the improvement of their professional competencies. Let us scrutinize the following descriptions given by the audience of this investigation. (i) The existing professional development is relevant. However, in the future there has to be a continuous improvement of the contemporary practices of professional development programs. Continuous revision, updating of the professional development training modules and approaches has to be in place to cope up with the changing world. Continuous assessment and improvement need to be conducted both on the content and process of the professional development program.

(ii) In an attempt to explain the appropriateness of professional development program one respondent in a simple phrase put it nothing at all. This is because the strategies frequently change institutionally. So that we face a quite number of programs coming into the area of game before we understand and/or realize the old. It is thus a futile exercise we are engaging.

It is quite clear that respondents cannot be expected to have one and agreed answer for the question of appropriateness. It is a matter of match or mismatch. When the existing PD satisfies the need and expectation of instructors, they could find it relevant; otherwise, they may consider it irrelevant/inappropriate (see Table 5).

In Adama University, teachers felt that the amount of skills and knowledge on teaching and the standard in their school had increased most significantly, and the level of commitment towards professional development had been rated the least. Overall, teachers felt that professional development had significantly increased the standard of teaching in their host institutions and the standard of pupil learning but had least impact on commitment to professional development generally. Some teachers felt that professional development had given them increased confidence and particularly appreciated the opportunity to exchange ideas with other teachers.

The positive impact of staff development is most likely to operate through a chain of events professional development activities affect the practices teachers have in their programs, and these practices in turn affect students' continuous performance [30]. Staff training can also help providers plan enriching activities, connect with participants' families, and communicate with community stakeholders: all of which are elements of high quality programs $[32,33]$.

Table 6 clearly notified that only 3.4 percent of the respondents reacted favorably, and 0.8 percent of them are found to have indifferent attitudes toward the professional development practices in place. The rest, almost the majority of the respondents (95.8), reacted, as they have unfavorable attitudes toward the professional development training currently in place. A moderate variation within the respondents in attitudes toward the teachers' professional development initiatives was the trends of the research findings under consideration as the standard deviation is equal to 6.8 .

In an interview conducted with one senior lecturer in Adama University, he expressed how together with his colleagues look upon the existing professional development training experience. 
TABLE 4: Teachers perceptions on the implementation of PDP.

\begin{tabular}{|c|c|c|c|c|c|}
\hline \multicolumn{6}{|c|}{ Teachers perception of professional development events } \\
\hline & $N$ & Minimum & Maximum & Mean & Std. deviation \\
\hline $\begin{array}{l}\text { Needs identified in my performance reviews have been met } \\
\text { through professional development }(\mathrm{PD})\end{array}$ & 120 & .00 & 4.00 & 2.2333 & .91425 \\
\hline $\begin{array}{l}\text { PD generally meets the needs of the institution rather than me } \\
\text { personally }\end{array}$ & 120 & .00 & 4.00 & 2.4667 & .94321 \\
\hline $\begin{array}{l}\text { I feel that I have a part in setting the agenda for professional } \\
\text { in-service training days }\end{array}$ & 120 & .00 & 4.00 & 2.1250 & 1.08900 \\
\hline $\begin{array}{l}\text { I feel that too many training days are driven by university } \\
\text { academic program }\end{array}$ & 120 & .00 & 4.00 & 2.1167 & 1.08607 \\
\hline PD providers think of it mainly as a commercial activity & 120 & .00 & 4.00 & 2.1667 & 1.08723 \\
\hline $\begin{array}{l}\text { PD provides me the opportunity to improve my teaching } \\
\text { awareness and skills }\end{array}$ & 120 & .00 & 4.00 & 2.7667 & .92340 \\
\hline
\end{tabular}

TABLE 5: Teachers perceptions of PDPs to improve standard of educational activities.

\begin{tabular}{lcccc}
\hline \multicolumn{5}{c}{ To what extent over the last 5 years PDPs have improved standards of educational activities } \\
& $N$ & Minimum & Maximum & Mean \\
\hline The standard of teaching in your college & 120 & .00 & 5.00 & 3.2167 \\
The standard of pupil learning in your college & 120 & .00 & 5.00 & 1.15361 \\
The level of commitment to PD amongst teachers & 120 & .00 & 5.00 & 2.9500 \\
The amount of skills and knowledge amongst teachers & 120 & 1.00 & 5.00 & 2.9250 \\
Learning improvement generally & 120 & 1.00 & 5.00 & 3.2417 \\
\hline
\end{tabular}

TABLE 6: Overall attitudes of teachers toward the professional development trainings.

\begin{tabular}{lccccc}
\hline \multicolumn{2}{c}{ Unfavorable attitude } & \multicolumn{2}{c}{ Indifferent attitude } & \multicolumn{2}{c}{ Favorable attitude } \\
In number & In \% & In number & In \% & In number & In \% \\
\hline 115 & 95.8 & 1 & 0.8 & 4 & 3.4 \\
\hline
\end{tabular}

In a week we have two days each for two hours to come together to deal with Higher Diploma Program (HDP). Because we were not interested in the training program, we have a unique name for HDP. We call it "a Health Damaging Program." We were considering it as something "alone and frightened".

From the above annotations, it can generally be concluded that although teachers believe on the necessity of professional development, in practice, they have unfavorable predispositions toward the current endeavor. The interview offered by the above participant also verifies that some teachers feeling toward the current practice of professional development were not encouraging. This requires revisiting of the present PD practices critically. Recent work on teacher motivation provides evidence for links between teachers' motivation and their engagement, commitment, and persistence in teaching and their inclination to become involved in professional development [58].

In an effort to compare respondents mean attitude score towards the professional development practices, a two-way analysis of variance was preferred. See Table 7.
From the result depicted in Table 7, it can easily be inferred that there is no significant mean difference in the attitudes of staff members depending on their sex and the level of professional qualification. This means that respondents uniformly favor or disfavor the current professional development practices irrespective of their sex and academic status. On the other hand, it can easily be deduced from the table that $F$ value is significant for schools and teaching experience. The post-hoc analysis of variance (Tukey Test) further identified that staff members in school of engineering have significantly better attitudes score than other. The possible reason for this could be that school of engineering has been the oldest and the most experienced school that has experience for many kinds of training in general and teachers' professional training practices in particular. Consequently, it is supposed that this could bring the possession of positive attitude toward the current professional development practices.

Moreover, the post-hoc analysis of variance reveals that staff members with less experience in teaching have better attitudes toward the professional development practices than other. It is assumed that these instructors are relatively young as well as having less experience for teaching. As a result, they could develop interest for such trainings. Studies in the field of professional development critically argued that the amount of formal education and teaching experience could have relation to teacher change. In their study of 100 teachers and the change they demonstrated after participating in different types of professional development, Smith and Hofer [59] identified the following individual characteristics as influencing how much changed and in what ways teachers 
TABLE 7: The significance mean difference in attitudes score of respondents with respect to the variables, sex, academic rank, and college/schools.

\begin{tabular}{|c|c|c|c|c|c|c|}
\hline & & Sum of squares & Df & Mean square & $F$ & Sig. \\
\hline \multirow{3}{*}{ Sex } & Between groups & .231 & 1 & .231 & .005 & .945 \\
\hline & Within groups & 5633.769 & 118 & 47.744 & & \\
\hline & Total & 5634.000 & 119 & & & \\
\hline \multirow{3}{*}{ Academic rank } & Between groups & 95.438 & 4 & 23.860 & .495 & .739 \\
\hline & Within groups & 5538.562 & 115 & 48.161 & & \\
\hline & Total & 5634.000 & 119 & & & \\
\hline \multirow{3}{*}{ Experience in teaching } & Between groups & 417.523 & 2 & 208.76 & 4.503 & .016 \\
\hline & Within groups & 5424.345 & 117 & 46.36 & & \\
\hline & Total & 5839.868 & 119 & & & \\
\hline \multirow{3}{*}{ College } & Between groups & 597.523 & 5 & 119.505 & 2.705 & .024 \\
\hline & Within groups & 5036.477 & 114 & 44.180 & & \\
\hline & Total & 5634.000 & 119 & & & \\
\hline
\end{tabular}

TABLE 8: Teachers' satisfaction with PD over the last 5 years.

\begin{tabular}{|c|c|c|c|c|c|}
\hline & $N$ & Minimum & Maximum & Mean & Std. deviation \\
\hline Your professional development & 120 & .00 & 5.00 & 2.9750 & 1.06481 \\
\hline Your promotion prospects & 120 & .00 & 5.00 & 2.2500 & 1.19699 \\
\hline Your teaching skills & 120 & .00 & 5.00 & 3.2167 & 1.10144 \\
\hline Your self-confidence/self-esteem & 120 & .00 & 5.00 & 3.2333 & 1.05904 \\
\hline Your desire to learn more & 120 & .00 & 5.00 & 3.3417 & 1.19168 \\
\hline Your students' learning outcomes & 120 & .00 & 5.00 & 3.2000 & 1.08929 \\
\hline \multirow[t]{2}{*}{ Your leadership skills } & 120 & .00 & 5.00 & 2.7917 & 1.23599 \\
\hline & & & & 3.0012 & \\
\hline
\end{tabular}

changed after participating in professional development. Those teachers with fewer years of experience changed more and teachers with low level of education (e.g., a bachelor's degree or less) changed more.

4.4. Improved Practices at Adama University. This part organized around respondents' feelings and arguments on the magnitude and intensity of the present professional development endeavor for promoting different academic and administrative executions. Explicitly, evidences obtained through respondents of this study about improved practices as result of professional development initiatives were catered and analyzed as demonstrated along Tables 8, 9, and 10.

Respondents were asked how much satisfied they had been with their professional development experience over the last 5 years. They were required to tick a box on a Likert type style items which ranged from 1: a very little extent to 5: to a very great extent. The overall score was 3.0012 indicating that most teachers were more satisfied than dissatisfied with their professional development experience $(N=120)$. On the other hand, although some teachers recognized the importance of keeping on top of new development through professional development initiatives, respondents unfavorably felt that professional development had least impact on their promotion prospects.
Professional development had also demonstrated less effect on leadership skills than on the development of teaching strategies and pupils' learning outcomes, and this is reflected in teachers' desire for more professional development concern with improving leadership and management skills. As a whole from the data described in Table 8, the professional development initiative has significant effect on teachers: the desire to learn more, their teaching skills, and empower their self-esteem. According to the respondent belief, the professional development effect was also equally significant to augment students learning outcome. However, although the above sectors seem higher than the average value, with regard to their promotion prospects, teachers seem dissatisfied. Moreover, teachers' improvement in developing leadership skills was not deliberated as other dimensions of the professional development plan had conducted. C.Livneh, H.Livneh [60] argued that two motivational factors predicted participation: high internal motivation to learn and high external motivation to learn (wanted career advancement or to network with others).

Academic staff members were asked to rank the amount of time they spent on a range of professional development activities. As indicated in Table 9, it is labeled that "improving teaching skills" was the most prioritized followed by "increasing subject knowledge" by significant amount of respondents. It means that instructors preferred to spend much time on many of their deficiencies related to classroom 
TABLE 9: The amount of time teachers spent on a range of PD activities.

\begin{tabular}{lcccc}
\hline & \multicolumn{2}{c}{ Ranking the amount of time you spent on a range of PD activities. } & \\
& $N$ & Minimum & Maximum & Mean \\
\hline Increasing subject knowledge & 120 & 1.00 & 6.00 & 3.1917 \\
Improving teaching skills & 120 & 1.00 & 6.00 & $2 \mathrm{nd}$ \\
Extending leadership skills & 120 & 1.00 & 6.00 & $1 \mathrm{st}$ \\
Developing other professional skills & 120 & 1.00 & 6.00 & 3.9667 \\
Personal career development & 120 & 1.00 & 6.00 & 3.6583 \\
Reflecting on values & 120 & 1.00 & 6.00 & 3.8583 \\
\hline
\end{tabular}

TABLE 10: Teachers justification of their involvement in range of PD activities.

\begin{tabular}{|c|c|c|c|c|c|}
\hline \multicolumn{6}{|c|}{ Ranking the reasons for your involvement in PD activities } \\
\hline & $N$ & Minimum & Maximum & Mean & Rank \\
\hline Personal interests & 120 & .00 & 6.00 & 3.6667 & 4th \\
\hline Performance management targets & 120 & 1.00 & 6.00 & 3.9167 & 5 th \\
\hline Institutional development plan & 120 & 1.00 & 6.00 & 2.7833 & 1 st \\
\hline PDP coordinating office action plan & 120 & 1.00 & 6.00 & 3.6167 & $3 \mathrm{rd}$ \\
\hline Local priorities/initiatives & 120 & 1.00 & 6.00 & 3.9333 & 6th \\
\hline National priorities/initiatives & 120 & 1.00 & 6.00 & 3.2917 & 2nd \\
\hline
\end{tabular}

teaching. Perhaps increasing the subject knowledge could be actualized through further long-term training for junior staff members. At the same time, some senior staff could prefer the continuous professional development practices to keep in touch with current findings and innovations specific to their area of interest.

From Table 9, it is quite possible to infer that "reflecting on values" and "extending leadership/management skills" were the least prioritized in terms of spending time as the area of professional development training initiatives. Teachers responded in this way; perhaps, these were not the immediate need of them in current situations. Generally, respondents would like to strengthen their knowledge and skills in teaching and subject specific contents as the effect of professional development initiatives. Researchers in the field of professional development put it that career development and acquisition of new knowledge and skills to play new roles should be the imperatives of surviving, adapting, and evolving.

Respondents in general justified their reasons of participation of professional development activities. Accordingly, as they have asked to rank their reasons for taking part in many of professional development practices, the majority prioritized institutional development plan as number one reason which was followed by national priorities/initiatives.

It was found from the study that improving or rather enhancing the professional competencies of academic staff of the university is of crucial importance, and is critical to any success colleges and universities have with diversity education. As a way of keeping staff current in their respective fields, the most forward thinking institutions must incorporate need to staff development into the fulfillment of individual as well as institutional needs. Such activities are critical in the face of increasingly diverse campuses and in the light of scholarship and global diversity that has transformed knowledge base [61].
4.4.1. Individual Contributions of Professional Development. If we believe that one purpose of teaching is to improve the self-concept of students, then it is important that teachers themselves maintain a healthy self-concept. If we wish our institution to help students develop higher level thinking skills, then the cognitive development of teachers becomes critical [62]. Teachers cannot assist their students in developing moral reasoning skills unless they reasonably good physical health will find it difficult to deal with the demands of the teaching day, let alone serve as a model of healthy living for students. We call these areas of teacher development [63]. In this respect, respondents in an interview were added the following comments.

(i) Things, events, thought are changing at faster rate; to cope up with such dynamic situation, the need to change our education system is imperative. For making those instructors to sufficiently equip with professional knowledge, trainings are necessary and indeed they are very valuable. It is believed that one way to augment the professional competencies of instructors is through provision of professional development training. Thus the usefulness of professional development activities to improve instructors' expertises should be considered.

(ii) As one component of the professional development training, trainees are expected to carry on action research at least in group. I suggest that when action research is carried out in group it will have some value, especially in developing team spirit, to solve problem collaboratively. As a whole, I can say that action research could bring change on the level of instructors' professional competencies and the environment of teaching and learning in general.

Thus as a way of individual improvement and a means for professional empowerment the need to be involved 
in professional development options like action research is imperative as the above respondents unanimously and robustly underlined it.

\subsubsection{Institutional Contributions of Professional Develop-} ment. Institutional culture and professional development are interactive. The culture to some extent determines what types of professional development are feasible and certainly can impact the success level of development programs. Conversely, professional development has been a significant factor in almost all successful institutional improvement efforts. Thus, it behooves those committed to professional development and institutional improvement to closely examine institutional culture (Gratch, 2001) [61,63].

4.5. Analysis of Data Received through Observation Checklist. In general, the researcher using direct and systematic observation recognized that the absence of professional development program in the university organizational structure, clear mission and vision, defined and well-articulated policy, strategic plan, representatives in university senate meetings, adequate, well-identified, and preserved training facilities, and unit library were problems of Adama University that in one way or another negatively affected the provision of invaluable professional development trainings. Moreover, the existence of professional development center to only the main campus of the university was another critical problem for provision of judicious professional assistance and followup of the professional development training deliberations. During the time of the observation and interview conducted with some teachers, to Adama University the location of the training center has not been attractive. It means that, since it is relegated to the peripheral position, many staff complain that they were not benefited to get immediate and timely assistance from the given center. Researchers and scholars in the field of professional development consistently suggested that the commitment and consistent followup of university administration in provision of necessary facilities and resources need to be prioritized for playing a leading role [22, 63]. Moreover, the need to have well-articulated professional development policy is instrumental in the attainment of its aims and objectives.

\section{Conclusions}

It is to be recalled that the study was aimed at exploring the practices of teachers' professional development at Adama University. In doing so, the following basic questions were constructed.

(i) What types of professional development frameworks were being provided?

(ii) What supports have been in place to facilitate the implementation of professional development initiatives?

(iii) To what extent instructors were satisfied with the $\mathrm{PD}$ opportunities? (iv) How can quantitative and qualitative difference be secured on teachers' behavior and the existing institutional culture through professional development programs?

In an attempt to seek answers to the above research questions, the researcher established the following findings.

5.1. Regarding the Typology of the Professional Development Program Enacted. The respondents in an attempt to enunciate the meaning of professional development in the context of their practice provide evidence of the complex nature of the concept as argued in the literature. From the explanation given, it was not difficult to conclude that many of the instructors and academic leaders had not been previously given any thought to professional development, and therefore the notion was essentially unfamiliar to them. Overall, though continuous academic and professional development has been perceived as the most useful avenue of teachers continuous and lifelong learning, for the most part, it is relegated to ad-hoc committees or interested group or institutional units in the system of university education/training. Moreover, among all the frameworks for professional development programs, training was the dominantly used mode of professional development practices. And, two training centers/programs, namely, ADRC and HDP, were exclusively played central role in the delivery of the several types of professional development trainings. In general, it can be argued that there was no institutionalized structure for organizing continuous professional development programs in Adama University. It was found that the professional development activities were seasonal rather than continuous. Although the literature on professional development in higher education emphasises continuity, variety, and collaboration, the existing reality was far from these.

5.2. The Implementation of Professional Development Program. In the course of professional development practices, there was a significance difference between the dream and reality. The gap between dreams and realities in the implementation of teachers' professional development practices is identical across gender disparities. The university, although it put in its blue print the importance of certain requisites, as the allocation of adequate resources, and the provision of support from colleagues and program leaders as well as the consideration of adequate time, in practice, however, were not fulfilled.

5.3. On the Appropriateness of Professional Development Program. In principle teachers' perceptions on the indispensability of professional development programs to augment the level of educational activities were positive. However, in response to open-ended items of the questionnaires, only 3.4 percent of the respondents reacted favorably, and 0.8 percent of them were found to have indifferent attitudes toward the professional development practices in place. The rest, almost the majority of the respondents (95.8) reacted, as they have unfavorable attitudes toward the professional development 
training currently in place. The analysis of variance, $F$ test demonstrated that there were no significance differences among sex; academic rank and study sites with regard to teachers' attitudes toward the professional development practices. Meanwhile, $F$ value is significant for years of experience in the university.

The absence of PDP in the university organizational structure, clear mission and vision, defined and wellarticulated policy, strategic plan, representatives in university senate meetings, adequate, well-identified and -preserved training facilities, and unit library were problems of Adama University that in one way or another negatively affected the provision of invaluable professional development trainings.

\subsection{Improved Practices as a Result of Professional Development} Program. Teachers were preferred dominantly to spend their time on professional development activities in order to improve their teaching skills and increasing subject knowledge. Respondents insisted that the major reason why they were involved in the various professional development programs resulted from the need for institutional development plan and national priorities, than individuals' teachers' needs and interest. As a result, teachers' involvement in planning and enacting the professional development initiatives was either less regarded or totally neglected. It was found that the present system of professional development practice has little or no contribution to the promotional prospects and career development perspectives.

In a nutshell, the audience of this study stated that the existing system of professional development was a topdown approach, which is dominantly characterized by donor driven than demand driven. The place of teacher to develop, and fully participate in preparation of materials and institutionalization of the professional development program, was totally nonexistent. Moreover, they strongly and repeatedly commented that since there was no a system for need analysis, all the beneficiaries were not at the same point of satisfying position. Overall, as there was no a system to make a tracer study for making a followup of those participants who have been involved in a professional development training, it seems very difficult if not impossible to know the qualitative and quantitative differences brought in teachers behaviour as a result of the existing system of the professional development practices.

5.5. Suggestions for Future Practices: The Need to Have Alternative PDP Model. Overall, from the findings traced and the general conclusion drawn from this investigation, one can suggest an alternative, appropriate, and agreed model that fit to the present Ethiopian Universities Professional Development Program. The respondents in this study commented that the present professional development programs do not have a system to know the need of the customers; thus, a need assessment practice has to be in place. Respondents also repeatedly stated that there has to be system to make a followup to have adequate and reliable knowledge of the effect of the professional development initiatives. Moreover, respondents enthusiastically forwarded that one problem associated to the present system of teachers professional development was the lack of common vision. Thus, the need to have professional development policy is a prerequisite. Hence, it seems wise for an institution to develop an agreed model like the one discussed in Figure 1

\subsection{An Emerged Model of Teachers' Professional Development} Program. The model calls for three different types of continuous improvement. First, each of the six phases of the model (represented by the six outer circles) includes an internal cycle of professional development and formative evaluation. Formative evaluation is intended to improve a program rather than judge its value.

For example, after stakeholders have developed a tentative vision (phase 1), they complete a formative evaluation of their vision statement. Based on the evaluation, program developers may wish to revise the vision statement before moving on to the next phase of the model, assessing needs. Similarly, the needs assessment is evaluated and revised, if necessary, before moving on to the "establishing" phase, and so on. The presentation of the six phases of the model will be followed by the inclusion of some possible formative evaluation questions for each phase. Each institution, however, should develop its own formative evaluation questions, as well as a plan for gathering and assessing data to help answer those questions.

A second means for continuous improvement within the professional development model consists of the "continuation" of each phase, once it is initiated. Using vision building as an example, there will come a point in the program development process when stakeholders are ready to move on to the second phase, "assessing needs." However vision building does not end when needs assessment begins rather it continues through each of the remaining phases of program development. As vision building continues, more experience, better information, and deeper reflection will enable the vision to become more complete. The same holds true for each of the phases of program development. As each new phase begins, all of the phases previously initiated continue. The 3rd means of continuous improvement is the fact that one program development cycle leads to another. Eventually, the six-phase model ends with review and evaluation, but the end of one cycle simply initiates the beginning of a new cycle, as stakeholders reexamine their vision and other program components in the light of evaluation data. The next cycle may lead to minor or major program revisions, or an entirely new program.

To put all in a simple statement, whilst the rest of the world is coming to terms with the dramatically changing landscape of higher education institutions as centers of knowledge generation, dissemination, and consumption, it would have painful consequences if Ethiopia fails to act timely. Explicitly speaking, the Ethiopian university education system must overcome the dual challenges of teachers' professional development, namely, the precedent dilemma of negligence and the new challenges of globalization. Past problems are characterized by inattention and inaction of all parties particularly by government agencies and higher 


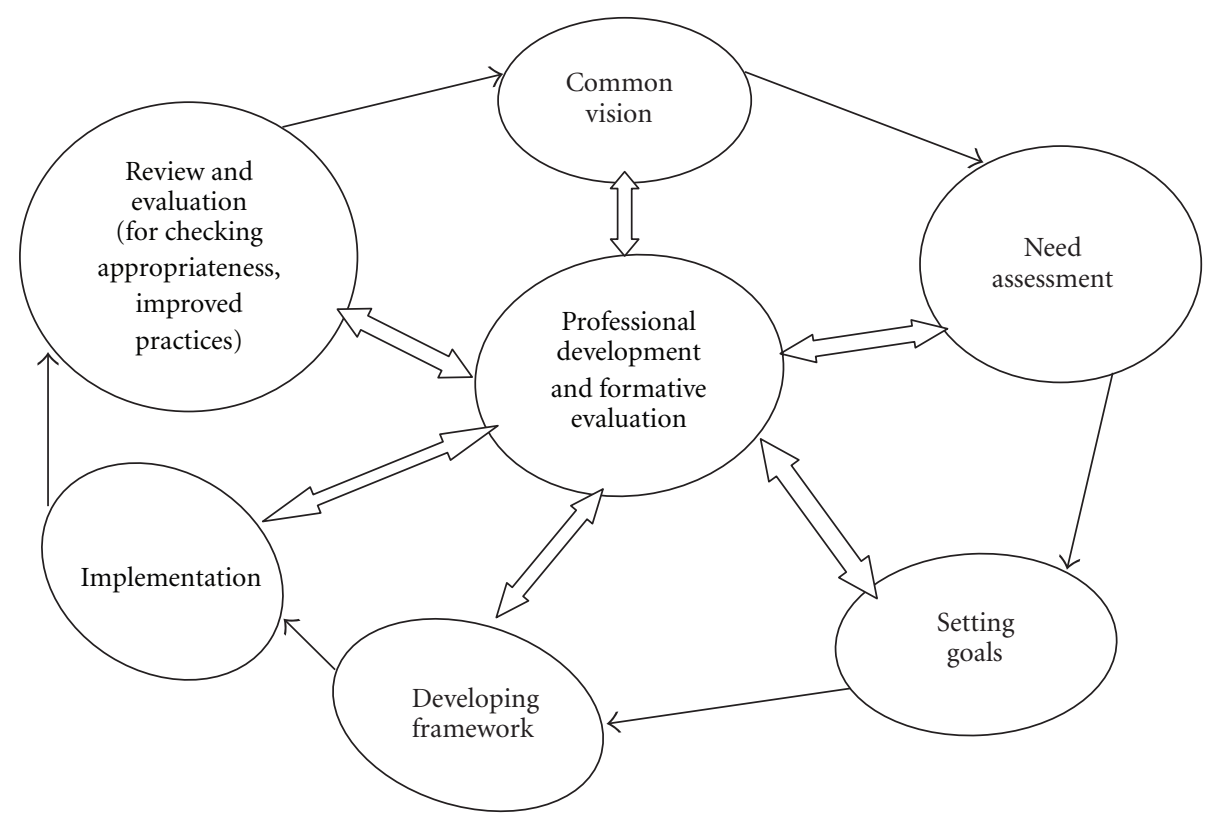

FIgURE 1: A model suggested for future deliberation of PDP in Ethiopian universities.

education institutions. On the other hand, higher education institutions should adjust themselves to the changing realities by abandoning their conventional and static stance and polish up their organizational structure, curricula, research, and teaching, and opening their doors to creating a learning society $[64,65]$.

\section{References}

[1] C. Milligan, "The Role of Virtual Learning Environments in the online delivery of staff Development," 1999, http: //www.icbl.hw.ac.uk/jtap-573/573r2.pdf.

[2] K. Ashcroft, "Emerging models of quality, relevance and standards in Ethiopia's higher institutions," The Ethiopian Journal of Education, vol. 13, no. 3, pp. 1-26, 2004.

[3] MOE, Ethiopia-Teacher Professional Development Profile (EQUIP1), 2008, http://www.glp.net/library/teachertraining// publisher/Klxp/document/Fteacher-training.

[4] MOE, A New Framework of Continuous Professional Development for Teachers, School Leaders and Educators in Ethiopia, 2009.

[5] A. J. Visscher and R. Coe, School Improvement through Performance Feedback, Swets \& Zeitlinger, Lisse, The Netherlands, 2002.

[6] D. Desta, "Observations and reflection of the Higher Education Teachers on quality of Teaching and Learning in Higher Education in Ethiopia," The Ethiopian Journal of Higher Education, vol. 1, no. 1, 2004.

[7] N. Abyot, "Pedagogical challenges among fresh instructors: a case of Mekele University," IER FLAMBEAU, vol. 9, no. 1, pp. $1-7,2001$.

[8] M. Adugna, Evaluating professional development of teacher educators in ethiopia: a case study of the higher diploma program at Addis Ababa University [M.S. thesis], University of Twente, Enschede, The Netherlands, 2006.
[9] R. Wade, "What makes a difference in in-service teacher education? A meta-analysis of research," Educational Leadership, vol. 42, no. 4, pp. 48-54, 1995.

[10] T. Guskey, Evaluating Professional Development, Corwin Press, California, Calif, USA, 2000.

[11] The Queens University of Belfast, Policy Statement, University of Cambridge, Staff Development Policies, 2006, http: //www.admin.cam.ac.uk/offices/personnel/staffdev/.

[12] University of Western Australia, "Staff Development," 2006, http://www.hr.nwa.edu.ac/policy/toc/appointment_\&_emplostaff_develomentyment/.

[13] University of Sussex, "StaffDevelopment," 2006, http://www. Sussex.ac.uk/units/staffing/staffdev/policies/staffdev.html.

[14] D. C. Teather, Staff Development in Higher Education, Kogan Page, New York, NY, USA, 2002.

[15] University of Cambridge, "Staff Development Policies," 2006, http://www.admin.cam.ac.uk/offices/personnel/staffdev//.

[16] S. C. Anyamele, Institutional management in higher education: a study of leadership approaches to quality improvement in university management. Nigerian and finnish cases [Ph.D. dissertation], Department of Education, University of Helsinki, 2004.

[17] C. Duke, The Learning University: Towards a New Paradigm. Buckingham and Bristol: The Society for Research into Higher Education, Open University Press, 1992.

[18] F. Bank and A. S. Mayes, Early Professional Development for Teachers, David Fulton, London, UK, 2001.

[19] S. Loucks-Horsley, P. W. Hewson, N. Love, and K. E. Stiles, Designing Professional Development for Teachers of Science and Mathematics, Corwin Press, California, Calif, USA, 1998.

[20] M. G. Fullan, The New Meaning of Educational Change, Teachers College Press, New York, NY, USA, 2nd edition, 2001.

[21] T. R. Guskey, "Professional development and teacher change," Teachers and Teaching: theory and Practice, vol. 8, no. 3, pp. 381-391, 2002.

[22] M. Temesgen, Design and development of online professional development program for teacher educators in Bahir Dar 
University [M.S. thesis], University of Twente, Enschede, The Netherlands, 2006.

[23] A. Ashworth and R. Harvey, Assessing Quality in Further and Higher Education, Jessica Kingsley, London, UK, 1994.

[24] TGE, -Education and Training Policy, EMPDA, Addis Ababa, Ethiopia, 1994.

[25] MOE, The Federal Democratic Republic of Ethiopia Education Sector Development Program III, Addis Ababa, Ethiopia, 2005.

[26] A. M. Brennen, "A comprehensive paper on staff development," 2001, http://www.soencouragement.org/comprehensive-paper-on-staff-developmemt.htm.

[27] M. G. Fullan, The New Meaning of Educational Change, Teachers College Press, New York, NY, USA, 2nd edition, 1991.

[28] D. J. Norris, "Quality of care offered by providers with differential patterns of workshop participation," Child \& Youth Care Forum, vol. 30, no. 2, pp. 111-121, 2001.

[29] P. A. Westat, "The longitudinal evaluation of school change and performance in title 1 schools," Final Report 2, 2001.

[30] M. A. Gambone, A. M. Klem, and J. P. Connell, Finding out What Matters for Youth: Testing Key Links in a Community Action Framework for Youth Development. Philadelphia: Youth Development Strategies and Institute for Research and Reform in Education, 2002, http://www.ydsi. org/YDSI/pdf/WhatMatters.pdf.

[31] M. Seligson and P. Stahl, Bringing Yourself to Work: A Guide to Successful Staff Development in after-School Programs, Teachers College Press, New York, NY, USA, 2003.

[32] J. S. Eccles and J. A. Gootman, Community Programs to Promote Youth Development, National Academy Press, Washington, DC, USA, 2002.

[33] J. Tolman, K. Pittman, N. Yohalem, J. Thomases, and M. Trammel, Moving an Out-of-School Agenda: Lessons Across Cities, Forum for Youth Investment, Takoma Park, Md, USA, 2002.

[34] HERQA, Adama University Institutional Quality Audit Report, HERQA Publication Series 024, Addis Ababa, Ethiopia,2008.

[35] HERQA, Hawassa University Institutional Quality Audit Report, HERQA Publication Series 026, Addis Ababa, Ethiopia, 2008.

[36] HERQA, Haramaya University Institutional Quality Audit Report, HERQA Publication Series 025, Addis Ababa, Ethiopia, 2008.

[37] HERQA, University of Gondar Institutional Quality Audit Report, HERQA Publication Series 029, Addis Ababa, Ethiopia, 2008.

[38] HERQA, Mekelle University Institutional Quality Audit Report, HERQA Publication Series, Addis Ababa, Ethiopia, 2008.

[39] HERQA, Bahir Dar University Institutional Quality Audit Report, HERQA Publication Series 027, Addis Ababa, Ethiopia, 2008.

[40] HERQA, Arba Minch University Institutional Quality Audit Report, HERQA Publication Series 030, Addis Ababa, Ethiopia, 2008.

[41] J. W. Creswell, Qualitative Inquiry and Research Design: Choosing Among Five Approaches, Sage, Thousand Oaks, Calif, USA, 2nd edition, 2007.

[42] J. W. Creswell, Research Design: Qualitative, Quantitative, and Mixed Methods Approaches, Sage, Los Angeles, Calif, USA, 3rd edition, 2009.

[43] C. M. Roberts, The Dissertation Journey: A Practical and Comprehensive Guide to Planning, Writing, and Defending your Dissertation, Corwin Press, Thousand Oaks, Calif, USA, 2004.
[44] R. K. Yin, Case Study Research: Design and Methods, Sage, Los Angeles, Calif, USA, 4th edition, 2009.

[45] A. Amare et al., "Establishing the National Resource Center," in Proceeding of the National Conference Held at AAU, School of Graduate Studies Conference Hall Amist Kilo, Addis Ababa, Ethiopia, August 2000.

[46] MOE, Hand Book of TESO, Addis Ababa, Ethiopia, 2003.

[47] D. Spinney and D. Jordan, Higher Diploma Program for Teacher Educators Handbook, Ministry of Education, Addis Ababa, Ethiopia, 2004.

[48] M. Cochran-Smith and S. L. Lytle, "Beyond certainty: taking an inquiry stance on practice," in Teachers Caught in the Action: Professional Development that Matters, A. Lieberman and L. Miller, Eds., Teachers College Press, New York, NY, USA, 2001.

[49] N. Bahr, S. Dole, M. Bahr, G. Barton, and K. Davies, Longitudinal Evaluation of the Effectiveness of Professional Development Strategies, University of Queensland \& Bond University, Queensland, Australia, 2007.

[50] C. Peers, C. Diezmann, and J. Watters, "Supports and concerns for teacher professional growth during the implementation of a science curriculum innovation," Research in Science Education, vol. 33, no. 1, pp. 89-110, 2003.

[51] M. Fullan, "Change the terms for teacher learning," Journal of Staff Development, vol. 28, no. 3, pp. 35-36, 2007.

[52] P. V. Bredeson, Designs for Learning, SAGE, Thousand Oaks, Calif, USA, 2003.

[53] S. S. Kaagan, Reflective Staff Development Exercises for Educators, SAGE, Thousand Oaks, Calif, USA, 2004.

[54] V. Collinson, "Staff development by any other name: changing words or changing practices?" The Education Forum, vol. 64, pp. 124-132, 2000.

[55] I. A. Coetzer, "A survey and appraisal of outcomes-based education (OBE) in South Africa with reference to progressive education in America," Educare, vol. 30, pp. 73-93, 2001.

[56] C. Day, Developing Teachers: The Challenges of Lifelong Learning, Falmer, London, UK, 1999.

[57] A. E. Wheeler, "Bridging the North-South Divide in teacher education. Teacher education," La Formation des Maîtres, vol. 41, pp. 12-15, 2001.

[58] S. A. Karabenick and A. Conley, Teacher Motivation for Professional Development, Math and Science PartnershipMotivation Assessment Program, University of Michigan, Ann Arbor, Michigan, 2011, http://mspmap.org/wp-content/. uploads/2012/01/Teacher-0PDM.pdf.

[59] C. Smith and J. Hofer, The Characteristics and Concerns of Adult Basic Education Teachers, National Center for the Study of Adult Learning and Literacy, Boston, Mass, USA, 2003.

[60] C. Livneh and H. Livneh, "Continuing professional education among educators: predictors of participation in learning activities," Adult Education Quarterly, vol. 49, no. 2, pp. 91$106,1999$.

[61] A. Gatch, "The culture of teaching and beginning teacher development," Teacher Education Quarterly, vol. 28, no. 4, pp. 121-136, 2001.

[62] C. D. Glickman, S. P. Gordon, and J. M. Ross-Gordon, Super Vision and Instructional Leadership: A Developmental Approach, Pearson Education, Boston, Mass, USA, 7th edition, 2007.

[63] G. Stephen, Professional Development for School Improvement: Empowering Learning Communities, Pearson Education, Boston, Mass, USA, 2004. 
[64] T. Semela, "Adult and continuing education in post-secondary institutions in Ethiopia: policy, practice, and challenges," European Journal of Social Sciences, vol. 13, no. 1, pp. 108-126, 2010.

[65] Y. Teshome, "The status and challenges of ethiopian higher education system: contribution to development," Ethiopian Journal of Higher Education, vol. 1, no. 1, pp. 1-20, 2004. 


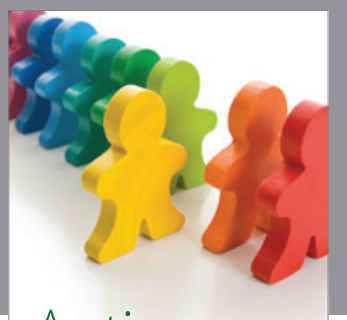

Autism

Research and Treatment
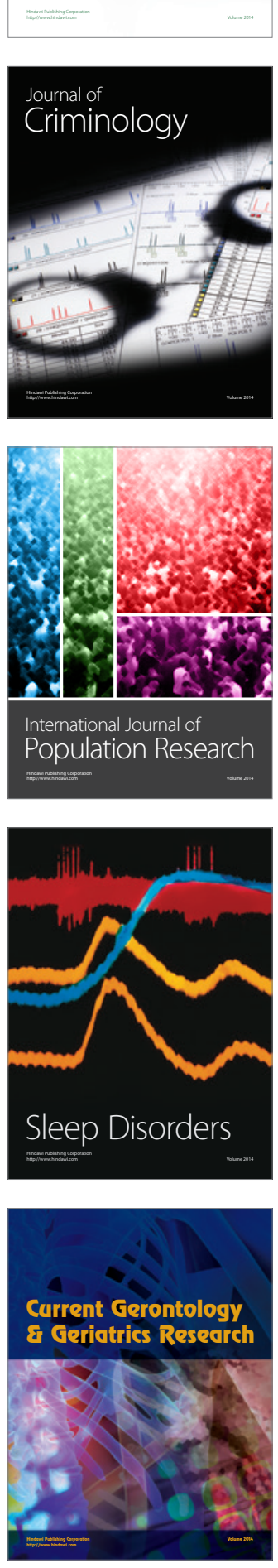
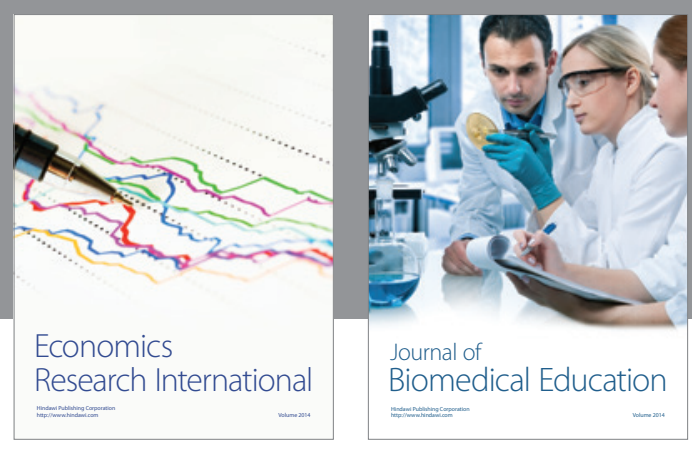

Journal of

Biomedical Education

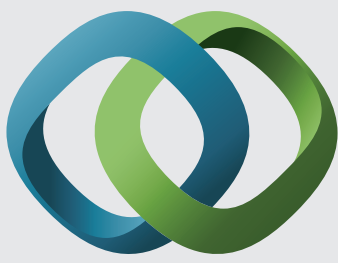

\section{Hindawi}

Submit your manuscripts at

http://www.hindawi.com
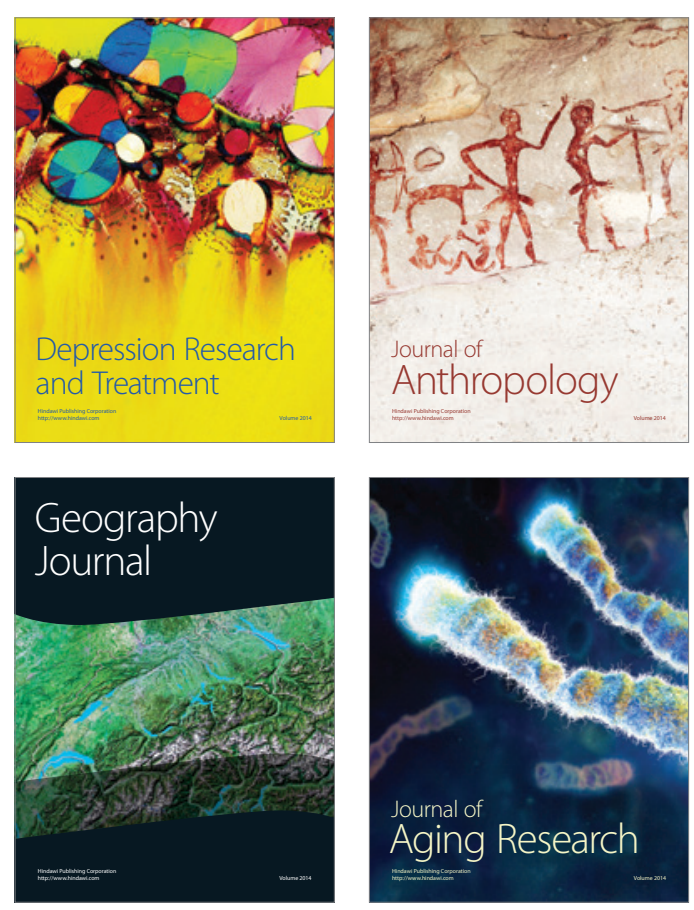

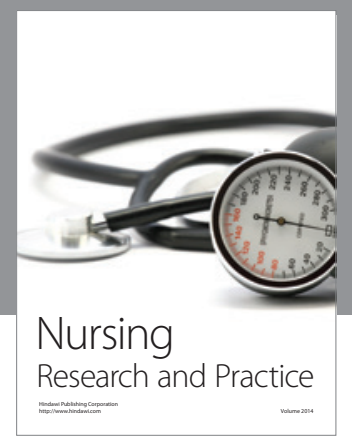

Nursing

Research and Practice

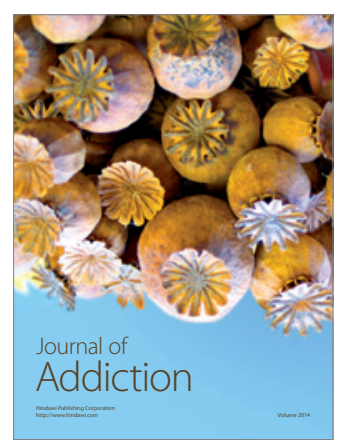

Child Development

Research

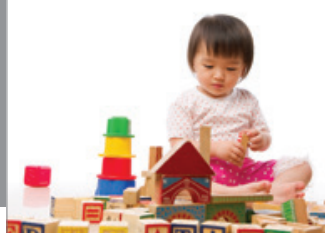

迥
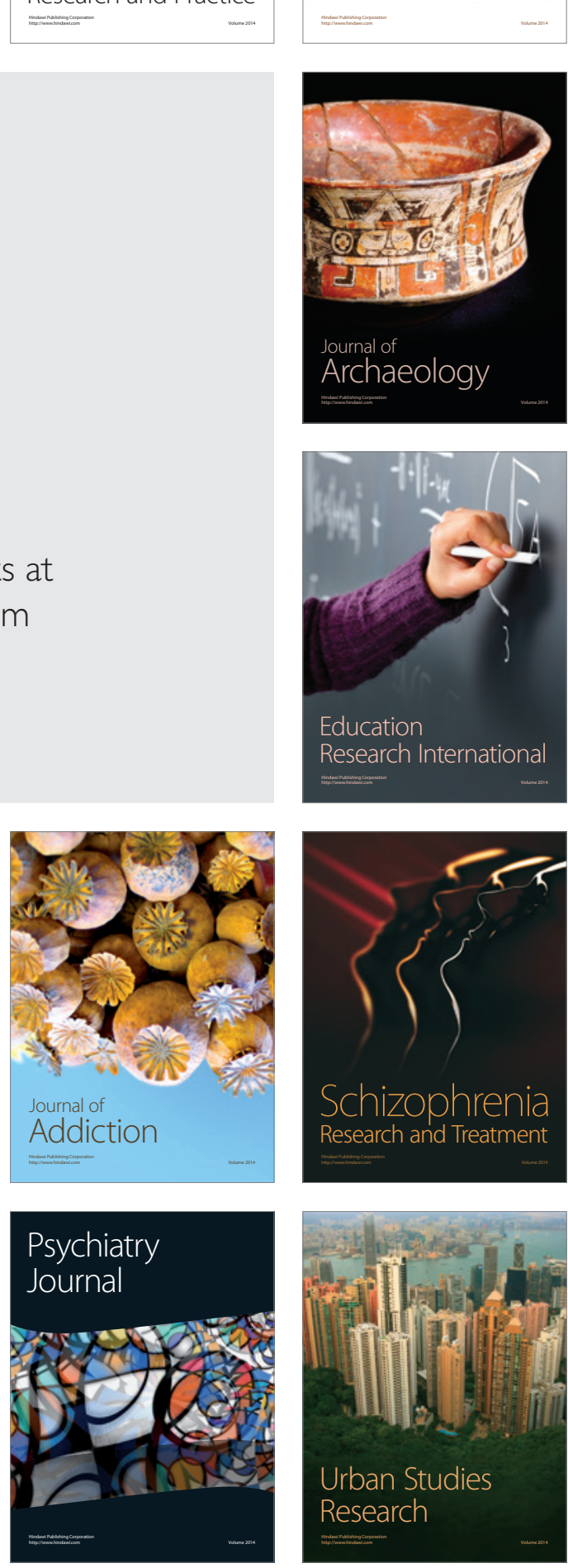